\title{
LA MINERÍA LEONESA DEL CARBÓN DURANTE LA AUTARQUÍA
}

\author{
Jesús SÁNCHEZ MELADO \\ Universidad de Valladolid
}

\begin{abstract}
RESUMEN: A pesar de su desfavorable posición competitiva, la industria nacional del carbón ha logrado sobrevivir gracias a una intensa protección, uno de cuyos puntos culminantes se encuentra en los años autárquicos. Durante esas dos décadas, la Administración, debido a la escasez de otras fuentes energéticas y a las propias características del modelo económico, impulsó de tal forma la industria carbonera que ésta alcanzó una desorbitada importancia económica y social. La minería leonesa es un claro exponente tanto de ese proceso de desmedido crecimiento como de las notables transformaciones territoriales a él asociadas.
\end{abstract}

PALABRAS CLAVE: crisis, minería, intervención, autarquía, cambios territoriales.

ABSTRACT: In spite of its unfavorable competitive situation, the national industry of the coal has been able to survive thanks to an intense protection. This protection reached one of its high points in the autarkic years. During those two decades, due to the shortage of other energy sources and to the own characteristics of the economic model, the Government encouraged intensely the coal industry and this obtained an economic and social disproportionate importance. The mining in the province of León is a good example of that process of excessive growth and of the remarkable territorial transformations caused by him.

KEYWORDS: crisis, mining, intervention, autarchy, territorial changes.

Los años cuarenta y cincuenta fueron decisivos para la industria nacional del carbón. Durante esas dos décadas surgieron o se desarrollaron muchas de las compañías que se iban a convertir en protagonistas de su devenir. En la provincia de León, Minero Siderúrgica de Ponferrada aumentó su producción un 75 por 100; Antracitas de Gaiztarro, un 69 por 100; la Vasco-Leonesa, un 298 por 100; Hulleras de Sabero, un 22 por 100; Antracitas de Fabero, que no se encontraba entre los productores de carbón en 1940, veinte años después era la tercera empresa carbonera leonesa por su volumen de actividad.

Al despuntar la década de los sesenta, la presencia de más empresas y el aumento de tamaño de las principales constituían los resultados más visibles de 
cuanto había acontecido a lo largo de los veinte años anteriores en la minería del carbón. Pero la realidad era que la Administración, con su política carbonera, había ido conformando un sector adaptado a las necesidades de una economía cerrada y atrasada, como lo era la España de los años cuarenta, pero incapaz de responder a los cambios que se estaban desencadenando en el mundo.

Unos cambios ante los que algunos países europeos no tardaron en reaccionar. Los trabajos iniciados con la declaración de Schuman de 9 de mayo de 1950 culminaron el 18 de abril de 1951 con la creación en París de la Comunidad Europea del Carbón y del Acero. Sin embargo, la firma del Tratado CECA tenía como escenario un mundo en el que el carbón se batía en retirada en muchos de sus tradicionales mercados. Sin el férreo control salarial que caracterizaba a la autarquía española, los precios del carbón en el mercado internacional experimentaban continuos incrementos, fruto de la presión de unos costes de personal al alza en una actividad intensiva en trabajo.

Por el contrario, la cotización del petróleo apenas varió entre 1945 y 1970. Consecuentemente, la sustitución del carbón por el crudo, fenómeno perceptible desde principios del siglo XX, se aceleró al terminar la Segunda Guerra Mundial. Al petróleo se sumaba ahora el gas natural en ese proceso de desplazamiento del combustible sólido como energía primaria. Un proceso que encontraba su razón de ser no sólo en la distinta evolución de los precios de las diversas fuentes de energía, el giro de la demanda hacia el petróleo y el gas natural tenía también mucho que ver con la facilidad de manejo de estas sustancias, y, sobre todo, con el aumento del nivel de vida y los profundos cambios tecnológicos que estaban teniendo lugar en los países desarrollados. Así, mientras el peso del carbón en la demanda mundial de energía primaria descendía desde el 71 por 100 al 49 por 100 entre 1938 y 1960, el del petróleo y el gas natural ascendía desde el 26 al 48 por $100^{1}$.

Por supuesto, el carbón no retrocedió en todos sus mercados. En algunos, como el siderúrgico, continuaba siendo esencial. Pero aquí, los elevados requisitos de calidad no permitían la entrada a todos los productores.

En este contexto tuvo lugar la evolución de la minería leonesa. Bien es verdad que la peculiar política de nuestro país impidió, al menos hasta mediar la década de los años cincuenta, que los españoles tomáramos conciencia clara de lo que estaba ocurriendo más allá de nuestras fronteras.

${ }^{1}$ García Alonso, José María y Juan E. Iranzo Martín (1988). La energía en la economía mundial y en España, Madrid: Editorial AC. 


\section{LA POLÍTICA CARBONERA DE UN PAÍS AISLADO Y SIN RE- CURSOS}

La etapa autárquica supuso un nuevo período de crecimiento de la producción nacional de carbón. Ante la escasez de otras fuentes energéticas y las dificultades casi insalvables, al menos durante los años cuarenta, para adquirir recursos energéticos en el exterior, los planteamientos económicos de este período - fruto de la ideología del régimen, de los acontecimientos internacionales y de la escasez de divisas - no dejaban otra alternativa, para atender las necesidades derivadas de la reconstrucción y la industrialización, que fomentar la producción de carbón. Una producción que, al finalizar la contienda civil, resultaba claramente insuficiente para satisfacer la demanda. Ante esta situación y la práctica suspensión de las importaciones - que durante las dos décadas autárquicas únicamente representaron el 5 por 100 de la oferta total—, garantizar el abastecimiento y evitar que la escasez impulsara alzas desmedidas en los precios se convirtieron en los principales objetivos de la política carbonera, en tanto que el problema de la falta de competitividad del carbón nacional, tan acuciante en los años anteriores a la Guerra Civil, era ahora irrelevante.

Siguiendo la misma lógica aplicada en otros sectores, la intensa intervención estatal se plasmó en un estricto control de la distribución del carbón, en la fijación oficial de los precios de la antracita y de la hulla (para favorecer el desarrollo industrial, sus cotizaciones se establecieron, en términos reales, por debajo de las vigentes antes de la guerra), y en un amplio abanico de medidas tendentes a fomentar la producción.

La Comisión para la Distribución del Carbón, creada en 1941, fue el organismo encargado de fijar zonas de venta a los productores y cupos para los distintos consumos, en un intento de afrontar el apremiante problema de la escasez mediante la intervención total del mercado. Ya antes incluso de su creación, la insuficiencia de la producción de hulla para atender las necesidades de la industria nacional había motivado prohibiciones y limitaciones a sus usos domésticos. Unas limitaciones que se mantuvieron durante varios años y que favorecieron la demanda de antracita.

Con el objetivo de afrontar el problema de la penuria energética y estimular la extracción de carbón, la Administración puso en práctica un amplio abanico de medidas, muchas de ellas encaminadas a superar uno de los principales obstáculos con que tropezaba el necesario incremento de la producción: la escasez de mano de obra. Así, para frenar el absentismo o aumentar el tiempo efectivo de trabajo se entretejió un complicado entramado de incentivos en el que tenían cabida desde el 
pago a los trabajadores de primas de asistencia y a la sobreproducción, hasta la exención del servicio militar en filas, pasando por la autorización para trabajar en domingo y remunerar las vacaciones de los obreros, la creación de economatos o la construcción de viviendas en las cuencas mineras.

Un conjunto de medidas que encontró su complemento en otro dirigido directamente a los empresarios: la creación de la Caja de Estímulo al Incremento de Producción y Rendimientos, precios más altos para las cantidades producidas por encima de las correspondientes al año base, preferencia a la importación de maquinaria y cemento con destino a la minería del carbón, sanciones a las empresas que no alcanzaran las producciones mínimas fijadas, posibilidad de que el INI interviniera para fomentar mejoras productivas, tarifas de transporte rebajadas, no aplicación de las restricciones eléctricas ${ }^{2}$, etc. El Gobierno, apremiado por la sequía y el déficit de carbón y electricidad, declaró, además, de «absoluta necesidad nacional» aquéllas instalaciones y obras que tuvieran relación directa con el incremento de la producción de carbón y energía eléctrica. Tal declaración significaba quedar al margen de las restricciones en el suministro de los materiales y elementos precisos para el desarrollo de la actividad, y disfrutar de facilidades para su importación. En 1945 fueron calificadas de «absoluta necesidad nacional» las labores de 59 productores de carbón.

Estas medidas se completaron con otra que, junto con la reserva del mercado español para el mineral nacional, resultaría fundamental para contrarrestar el efecto de unos precios de venta fijados oficialmente en unos niveles muy bajos comparados con los de preguerra. Una medida que se convertiría en una de las piezas clave de las expectativas de beneficios que atrajeron al negocio minero a nuevos empresarios e indujeron a los existentes a ampliar sus explotaciones. Se trata del control que la Administración ejerció sobre el más relevante de todos los costes de las empresas mineras: los gastos de personal. Obviamente, con unos ingresos limitados por unos precios intervenidos, las expectativas empresariales favorables requerían que los costes, de alguna manera, también lo estuvieran. De

${ }^{2}$ Una Orden de la Delegación Técnica de Restricciones, publicada el 9 de octubre de 1950 en el Diario de León, señalaba que «ante la gravísima situación sobre disponibilidades de energía eléctrica por el rápido agotamiento de los embalses, y en previsión de que sea preciso cortar totalmente el suministro si no se llega a alcanzar un régimen de precipitaciones que lo remedie, se hace preciso incrementar las restricciones en vista de que con las establecidas actualmente no se ha conseguido resultado sensible. En su consecuencia, a partir del martes día 10 del corriente, se cortará totalmente el suministro durante cuatro días semanales de 7 de la mañana a 7 de la tarde sin excepción alguna, salvo las minas de carbón». 
hecho, hasta 1956 el nivel real de los salarios en las minas leonesas se mantuvo muy por debajo del correspondiente a 1935.

El resultado de la política carbonera fue, según la Estadística Minera y Metalúrgica de España, el incremento de la producción nacional de hulla y antracita en un 54 por 100 entre 1940 y 1960, con una expansión más vigorosa de la producción antracitera (129 por 100) que de la hullera (44 por 100). Un resultado que puede considerarse mediocre si tenemos en cuenta que se consiguió a lo largo de dos décadas, $\mathrm{y}$, sobre todo, si lo comparamos con el logrado durante la fase expansiva de la Primera Guerra Mundial, cuando, en tan sólo cinco años, la producción nacional aumentó un 46 por 100.

Sin embargo, dicha expansión resultó desmedida y dio lugar a una industria sobredimensionada. Únicamente en el insostenible contexto autárquico parecía insuficiente, puesto que, efectivamente, al prescindir de las importaciones, los productores fueron incapaces de satisfacer la demanda, y de evitar que las situaciones de desabastecimiento en el mercado carbonero se convirtieran en la norma hasta 1955 , es decir, hasta que la oferta de energía primaria comenzó realmente a diversificarse.

Aunque, para situar las cosas en sus justos términos, es necesario reconocer que esa incapacidad se debió, en gran parte, no a que la capacidad de producción potencial resultara insuficiente, sino a la concurrencia de una serie de factores que no se encontraban bajo el control de las empresas mineras, como la escasez y la carestía de la maquinaria, la madera, los combustibles o los medios de transporte, que impidieron un mayor crecimiento de la producción; o a la propia intervención pública en el sector, que tuvo otro de sus máximos exponentes en el sistema de distribución del producto mediante cupos, cuyos beneficiarios no coincidían siempre con los más necesitados de mineral, lo que originó, además de los problemas de desabastecimiento, la aparición del mercado negro.

El cúmulo de todas estas circunstancias (precios de venta intervenidos, control salarial, incremento de otros costes de producción, etc.) terminó por repercutir negativamente en la rentabilidad de las empresas. Una circunstancia que plantea algunas dudas sobre la consideración que a menudo se hace de la autarquía como una «segunda edad de oro de la minería del carbón» ${ }^{3}$. El Sindicato Nacional del

\footnotetext{
${ }^{3}$ La expresión «nueva edad de oro» la utiliza, entre otros, GARCÍA ALONSO $(1986,117)$, un autor de cuyas ideas este trabajo es deudor en muchos aspectos. Coincidiendo en lo fundamental con su análisis de lo acontecido durante la autarquía; la discrepancia surge a la hora de concluir que de esos acontecimientos se derivara una etapa de auge o prosperidad para la minería nacional.
} 
Combustible, al referirse a los precios tasa de la hulla, que a finales de los cincuenta se aplicaban a 5,7 millones de toneladas (el 52 por 100 de la producción nacional), afirmaba: «El precio de este carbón es, en la mayoría de los casos, sensiblemente inferior al coste. Generalmente esta pérdida no se compensa con la venta de granos, por lo que el margen de rentabilidad de las empresas hulleras es nulo, salvo excepciones» ${ }^{4}$.

Es cierto que en esos momentos la coyuntura carbonera estaba ya experimentando un giro radical, y que, en consecuencia, lo que estaba aconteciendo al concluir la autarquía no se puede, sin más, hacer extensivo a los años anteriores. Pese a ello, existen argumentos que apoyan la idea de que la rentabilidad del sector no debió de ser especialmente brillante en ningún momento del largo período autárquico. Así, al menos, parecen sugerirlo las continuas quejas de las empresas, los innumerables cierres de explotaciones y los nada espectaculares beneficios de las secciones carboneras de las principales empresas mineras.

La pregunta que surge de inmediato es por qué en estas circunstancias -es decir, con una rentabilidad muy cuestionable - las empresas invirtieron e incrementaron su producción. La respuesta no es, por supuesto, ni simple ni sencilla. En una industria totalmente intervenida y esencial para la buena marcha del conjunto de la economía, caracterizada además por la escasez, probablemente los empresarios confiaban en que el poder político - tan interesado por las cuestiones mineras y más accesible, en definitiva, que las fuerzas ciegas del mercado - tarde o temprano adoptaría medidas para fomentar la actividad. Medidas que, como el control salarial, terminarían favoreciendo a las empresas e incrementando sus beneficios - obsérvese que, también en la actualidad, en un escenario considerablemente más complicado para el carbón nacional que el autárquico, la política expansiva de algunos empresarios mineros sólo encuentra explicación en las expectativas de que el trato de favor que la Administración otorga al sector se mantenga en el futuro-- De hecho, los problemas se intentaron resolver, invariablemente, apelando a la Administración: «Bien pronto [...] los aumentos alcanzados por diversos materiales, muy principalmente la madera, han absorbido dicho margen [de beneficio], obligándonos a plantear de nuevo ante el Gobierno la situación actual de la Industria Minera».

${ }^{4}$ Sindicato Nacional del Combustible (1961). La minería del carbón en España, Madrid: Artes Gráficas Sol, p. 50.

${ }^{5}$ Memoria de la Vasco-Leonesa correspondiente a 1946. 
Por otro lado, en una economía empobrecida, donde las posibilidades de elección eran escasas y la agricultura comenzaba su crisis estructural, es posible que los beneficios nominales atrajeran a pequeños empresarios no muy acostumbrados ni a considerar las amortizaciones como un coste ni a tener en cuenta la pérdida de poder adquisitivo del dinero. Finalmente, no se debe olvidar que el mercado negro pudo reportar sustanciales beneficios a los productores menos escrupulosos, y que, además, la Administración imponía a las empresas objetivos mínimos de producción.

Lo cierto fue que buscando los beneficios que aparentemente prometía el negocio carbonero y, ahora sí, al igual que en la etapa fuertemente expansiva de la Primera Guerra Mundial, proliferaron numerosas empresas marginales de dimensión ínfima, cuya supervivencia ni siquiera estaba garantizada en el artificioso entorno protector.

El coste relativamente reducido de la mano de obra, junto con la escasez de maquinaria, espoleó su uso intensivo y el consiguiente aumento del empleo. Según la Estadística Minera y Metalúrgica de España, el sector de la hulla y la antracita pasó de 51.634 obreros en 1940 a 83.401 en 1960, un incremento del 61,5 por 100, superior, por tanto, al de la producción.

Figura 1. Rendimientos en la minería nacional y leonesa de la hulla y la antracita, 19401960 (toneladas anuales por trabajador)

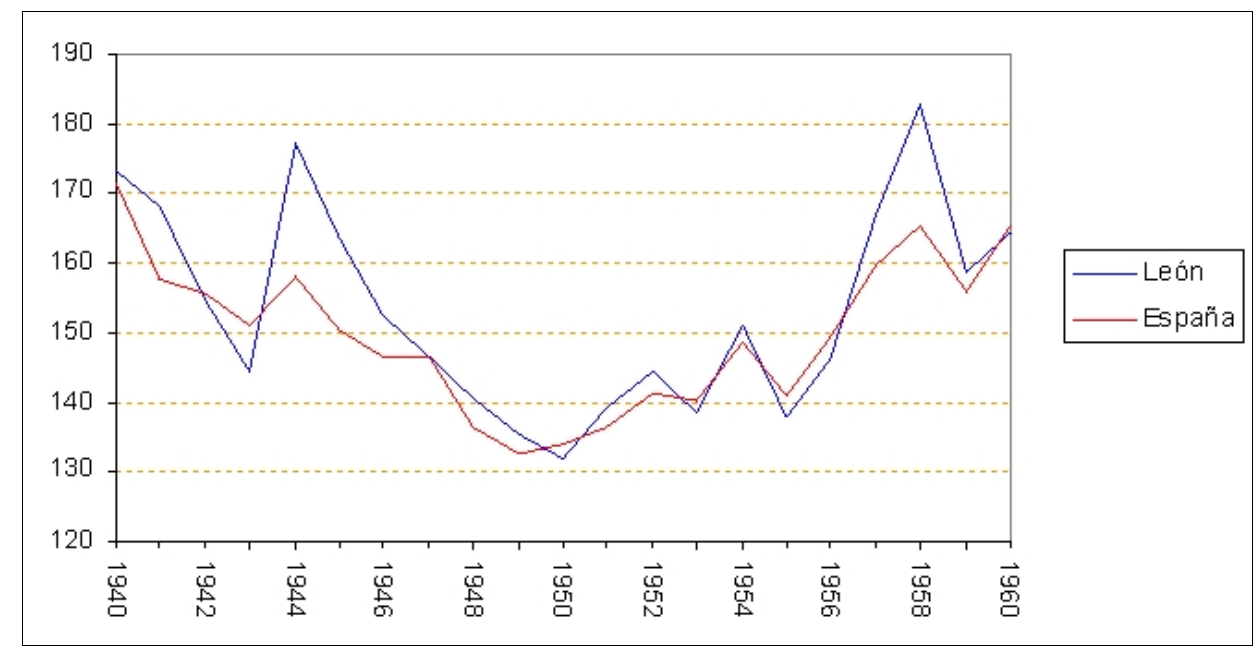

FUENTE: Estadística Minera y Metalúrgica de España 
No resulta extraño, sobre todo si tenemos en cuenta la proliferación de empresas marginales de capitalización mínima y la situación de penuria que vivió el país durante los años cuarenta, la evolución que siguieron los rendimientos, claramente decreciente hasta 1950 y de lenta recuperación a partir de esta fecha (figura 1), pero sin llegar a alcanzar los niveles de 1940 en el caso de la hulla, y, en el de la antracita, superándolos sólo a partir de 1957. El comportamiento de los rendimientos se erigía, nuevamente, como uno de los síntomas más claros de la precariedad de la industria española del carbón, y de que sus males de siempre seguían presentes.

Pero la caída de los rendimientos no era el único hecho preocupante. Tras la expansión de la producción carbonera, se ocultaban otros que arrojaban también dudas sobre su futuro. El más significativo fue el descenso que experimentó la participación del carbón en el consumo de energía primaria, al pasar del 88 por 100 en 1940 al 47 por 100 en $1960^{6}$. Esto significaba, sencillamente, que esta demanda aumentaba a un ritmo muy superior al de la producción de carbón, y que, consecuentemente, en su satisfacción participaban de forma creciente otras fuentes de energía. Ausentes del panorama energético español el uranio y el gas natural, el retroceso relativo del carbón se debió, durante los años cincuenta, al impulso de la energía hidráulica y, sobre todo, del petróleo. Este último pasó de representar el 9 por 100 del consumo de energía primaria en 1950, a suponer el 31 por 100 en 1960. Por su parte, la expansión de la potencia eléctrica instalada, que puso fin a las interrupciones periódicas del suministro en 1955, hizo que el consumo energético español empezara también a inclinarse hacia la electricidad.

La demanda y la oferta de carbón se igualaban por primera vez desde el final de la guerra ${ }^{7}$. El viejo fantasma del exceso de producción volvía a aparecer y la intensa intervención estatal en el sector, que perseguía garantizar los abastecimientos, empezaba a perder sentido. El resultado fue la progresiva liberalización del mercado y la sustitución de la política de apoyo a la producción por una política, similar a la de preguerra, de fomento al consumo. En definitiva, en la España de los años cincuenta, cada vez más lejos de la penuria de la década anterior, la demanda de energía primaria empezaba a responder a los mismos estímulos que la demanda mundial.

${ }^{6}$ SEN Rodríguez, Luis Carlos (1993). La minería leonesa del carbón, 1764-1959: una historia económica, León: Universidad de León, p. 311.

${ }^{7}$ COll MARTín, Sebastián y Carles SUdRIÀ I TRIAY (1987). El carbón en España, 1770-1961: una historia económica, Madrid: Turner, p. 560. 
Con estas características, la vulnerabilidad de la minería nacional del carbón era extrema; y su incapacidad para afrontar los cambios que empezaban a vislumbrarse al declinar la última década autárquica, manifiesta. Los empresarios mineros contemplaban con inquietud acontecimientos como la entrada en servicio de las primeras locomotoras diesel en algunos ferrocarriles (entre ellos el de La Robla) o el aumento de las tarifas de transporte ${ }^{8}$. Pero no eran nada comparados con lo que estaba por venir.

La competencia del petróleo y sus derivados, que se intensificó a partir de 1957, asestó un duro golpe a la industria nacional del carbón. Ese año, las importaciones de crudo crecieron un 72 por $100, \mathrm{y}$ al año siguiente volvieron a hacerlo un 22 por 100. En dos años las toneladas anuales de petróleo que entraban en nuestro país se habían duplicado largamente, alcanzando la cifra de 6,7 millones, cuando al despuntar la década de los cincuenta no llegaban al millón ${ }^{9}$. La senda alcista que hasta 1959 había seguido la producción de carbón se quebró. En sólo dos años la producción nacional cayó un 4,5 por 100, y la leonesa un 13,6 por 100. El retroceso fue especialmente preocupante en el sector de la antracita (de ahí el mayor descenso de la minería leonesa, productora de más del 70 por 100 de la antracita nacional): casi un 20 por 100 tanto en León como en el conjunto del país. En la caída de las ventas de este tipo de carbón, decía la Estadística Minera y Metalúrgica de España de 1960, se evidenciaba la influencia del gas butano, «que por su comodidad y reducido precio resulta un rival de consideración» ${ }^{10}$.

\section{LA CONSOLIDACIÓN DE LAS GRANDES COMPAÑÍAS MINERAS LEONESAS}

En un marco tan artificioso y lleno de matices como el autárquico, la producción leonesa de carbón aumentó un 93 por 100. Un crecimiento que, aunque sustancialmente más elevado que el experimentado por la producción nacional, también se quedó muy lejos del registrado entre 1914 y 1919, cuando la extracción de carbón en la provincia se triplicó. El comportamiento más dinámico de la minería en León se vio favorecido por el mayor peso que en ella tenía la antracita, y por la entrada en funcionamiento en julio de 1949 del primer grupo de la central

\footnotetext{
${ }^{8}$ Según el Sindicato Nacional del Combustible (1961), el aumento de las tarifas de transporte que tuvo lugar el 1 de agosto de 1959 supuso para el carbón un incremento del 49 por 100 en recorridos medios de 500 kilómetros, más del doble que el soportado por el resto de las mercancías, para las que ese incremento fue del 23 por 100.

${ }^{9}$ BANCO EXTERIOR DE ESPAÑA (1968). Hechos y cifras de la economía española, 1967, Madrid: Nuevas Gráficas, p. 117.

${ }^{10}$ Instituto Geológico y Minero de EsPaña: Estadística Minera de España (1960), p. 219.
} 
térmica de Compostilla (Endesa), un ejemplo relevante de la creciente importancia de los destinos termoeléctricos del carbón, pese a que, en 1959 con un 8 por 100 del consumo, estaban todavía muy lejos de alcanzar la trascendencia que tendrían en el futuro.

En consonancia con la evolución de la producción, el incremento del empleo también fue más intenso en la provincia de León que en el conjunto del país. En 1960 la plantilla carbonera leonesa, integrada por 21.825 trabajadores, duplicaba a la de 1940, año en el que se cifraron en 10.727 los puestos de trabajo generados por esta industria.

Los rendimientos siguieron la misma pauta que a escala nacional. Con una tendencia decreciente hasta 1950 y ascendente a partir de ese año, que finalmente se quebró en 1959. Esta ruptura resultó más brusca en la provincia debido al ya mencionado mayor peso de la antracita. El nivel de partida y de llegada de los rendimientos, como se aprecia en la figura 1, fue sustancialmente el mismo en León y en el conjunto del país, en ambos casos los rendimientos en 1960 eran más bajos que en 1940 .

Tanto la evolución de los rendimientos como la de la producción permiten identificar las tres fases por las que pasó la minería leonesa durante estos años: el prolongado período de estancamiento de los años cuarenta fue seguido por una fase expansiva, truncada en 1959 como consecuencia de la intensificación de la crisis carbonera (figura 2).

Figura 2. Producción leonesa de carbón, 1940-1960 (miles de toneladas)

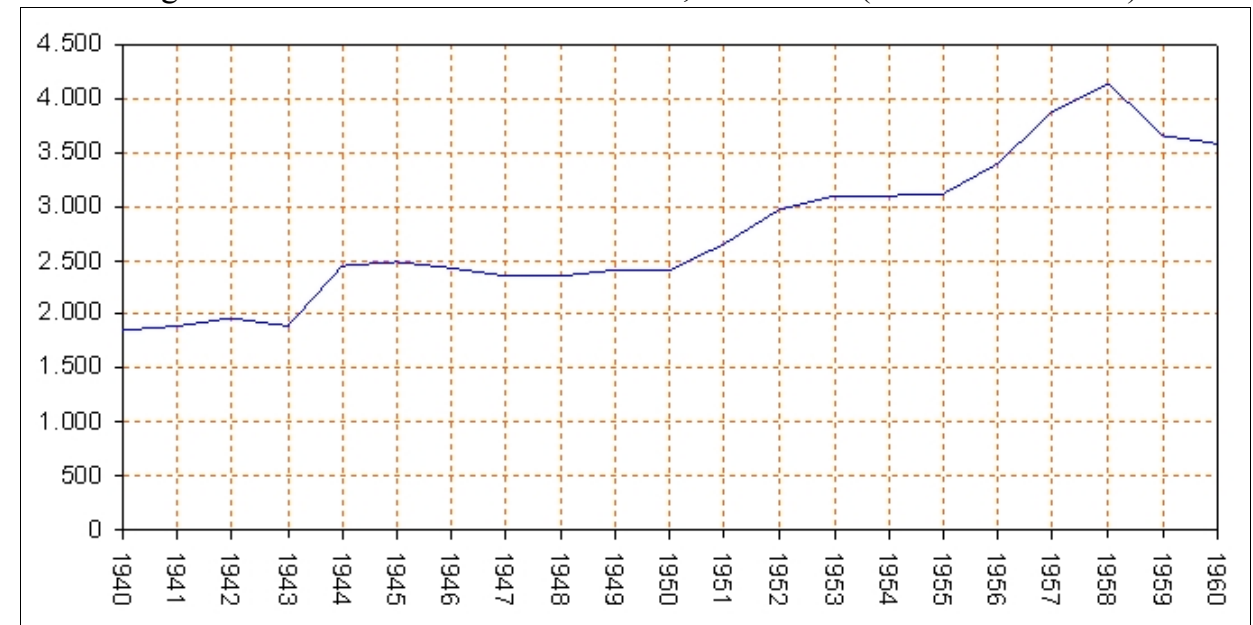

FUENTE: Estadística Minera y Metalúrgica de España 
La causa fundamental del estancamiento durante la primera década autárquica radicó en los problemas de transporte. En concreto, desempeñaron un papel esencial las deficiencias de los ferrocarriles y la escasez de gasolina para el arrastre hasta las estaciones de embarque.

Éste se puede considerar [los cargues en el ferrocarril] en este Distrito [León] un punto esencial, pues claro es que los ferrocarriles no cargan la producción que pueden, en las condiciones actuales, producir las minas, estando esta producción limitada y frenada por dicha causa, toda medida tendente al aumento de producción es inoperante. Debe, pues, antes que nada, ser resuelto este asunto ${ }^{11}$.

Los problemas del ferrocarril de La Robla y de Renfe impidieron que se pudiera dar salida a toda la producción, con la consiguiente acumulación de existencias, cuando, paradójicamente, en el conjunto del país la escasez generalizada de carbón se revelaba como uno de los contratiempos más acuciantes. Las dependencias de Hulleras de Sabero el 31 de diciembre de 1946, con 11.594 toneladas paralizadas por las dificultades de transporte, constituyen, dadas sus especiales relaciones con Ferrocarriles de La Robla, un ilustrativo ejemplo de esa situación.

En el ferrocarril de La Robla las deficiencias de cargue son igualmente extraordinarias. Lo demuestra el que la Sociedad Hulleras de Sabero, que tan íntimamente está ligada con la Sociedad propietaria del citado ferrocarril de La Robla a Bilbao, y que normalmente no tiene ninguna existencia en plaza, el 31 de diciembre de 1946 tenía una existencia de 4.872 toneladas de menudo lavado, 5.510 toneladas de «schlamms» y 1.212 de cok metalúrgico. Y si esto le sucedía a Hulleras de Sabero, es de suponer la falta de cargue de las demás minas de la zona ${ }^{12}$.

Por idéntico trance pasó la Vasco-Leonesa, cuya producción se mantuvo sistemáticamente por encima de las ventas entre 1946 y 1955. En esta situación tuvieron mucho que ver, al igual que en Sabero, las trabas relacionadas con el transporte ferroviario. En la memoria de 1948, la dirección de la compañía se lamentaba por la persistencia de este grave inconveniente:

Durante el último trimestre del ejercicio se ha agudizado de tal manera la escasez de material de ferrocarril que, de no resolverse satisfactoriamente,

11 Instituto Geológico y Minero De España: Estadística Minera y Metalúrgica de España (1946), p. 377.

12 Instituto Geológico y Minero De España: Estadística Minera y Metalúrgica de España (1946), pp. 375-376. 
puede abocarnos a tener que reducir nuestra producción para atemperarla a las entregas de material.

En el caso del productor de Ciñera-Matallana, las dificultades persistirían durante buena parte de los años cincuenta: «Los transportes de Renfe han mejorado durante el ejercicio y como consecuencia hemos podido hacer regularmente los cargues de nuestros carbones» se lee por primera vez en la memoria de la VascoLeonesa correspondiente a 1957.

Para tratar de paliar los inconvenientes planteados por la escasez de medios de transporte, la Administración insistía, una y otra vez, en la necesidad de incrementar y mejorar las instalaciones de lavado y clasificación, lo que permitiría terminar con el cargue de grandes tonelajes de «todo uno», cuyo contenido en cenizas llegaba a veces al 35 por 100. Este interés se plasmó en las autorizaciones de construcción y funcionamiento de numerosos lavaderos, aunque chocó con la renuencia de muchos pequeños y medianos empresarios que veían que, en un mercado muy poco exigente debido a la escasez, podían colocar sus carbones sin dificultad y sin necesidad de someterlos a costosos procesos para incrementar su calidad. Ante esta situación, a la Administración no le quedó otra alternativa que prohibir en 1948 la facturación en el ferrocarril de los carbones sucios. En un primer momento se prohibió el transporte de aquéllos cuyo porcentaje en cenizas excediera del 35 por 100, porcentaje que se fue reduciendo progresivamente.

Con este panorama, las dificultades relacionadas con la mecanización, el suministro de energía, el aprovisionamiento de madera o la escasez de mano de obra - problemas todos ellos de la minería leonesa en aquellos momentos, y, consecuentemente, también factores explicativos de la evolución de la actividad carbonera-, quedaban relegadas a un segundo lugar. Es cierto, por ejemplo, que ante la falta de divisas se denegó una gran parte de las peticiones de permisos de importación de maquinaria minera, pero no lo es menos que el acceso a dicha maquinaria difícilmente hubiera podido dar lugar a un incremento de la producción, dado el estado de los transportes. Igual razonamiento cabe realizar, evidentemente, con el resto de los factores antes mencionados.

La tabla 1 ofrece una visión panorámica, en lo que a la producción se refiere, de la situación inicial y final de la minería del carbón en León y en cada una de sus cuencas. Cuatro de ellas (La Magdalena, Cármenes-Villamanín, Ciñera-Matallana y el Bierzo) crecieron por encima de la media provincial, y vieron aumentar su importancia relativa dentro de la industria carbonera leonesa. Tanto Valderrueda como, sobre todo, Sabero perdieron peso en el conjunto provincial. Obsérvese el 
protagonismo de la minería berciana en el crecimiento de la producción leonesa, al que aportó más del 50 por 100.

\begin{tabular}{|c|c|c|c|c|c|c|}
\hline \multicolumn{7}{|c|}{ Tabla 1. Producción en las cuencas leonesas en 1940 y 1960} \\
\hline & \multicolumn{2}{|c|}{1940} & \multicolumn{2}{|c|}{1960} & \multicolumn{2}{|c|}{ Variación } \\
\hline & Toneladas & $\%$ & Toneladas & $\%$ & Absoluta & $\%$ \\
\hline El Bierzo & 621.874 & 33,45 & 1.505 .959 & 42,02 & 884.085 & 142,16 \\
\hline Villablino & 634.236 & 34,12 & 1.005 .236 & 28,05 & 371.000 & 58,50 \\
\hline Ciñera-Matallana & 204.988 & 11,03 & 536.684 & 14,97 & 331.696 & 161,81 \\
\hline Sabero & 322.588 & 17,35 & 353.999 & 9,88 & 31.411 & 9,74 \\
\hline Valderrueda & 58.829 & 3,16 & 96.488 & 2,69 & 37.659 & 64,01 \\
\hline La Magdalena & 13.340 & 0,72 & 73.852 & 2,06 & 60.512 & 453,61 \\
\hline Cármenes-Vill. & 3.256 & 0,18 & 11.786 & 0,33 & 8.530 & 261,98 \\
\hline Totales & 1.859 .111 & 100,00 & 3.584 .004 & 100,00 & 1.724 .893 & 92,78 \\
\hline
\end{tabular}

El número de empresas aumentó un 53 por 100 (tabla 2). En Ciñera-Matallana, Sabero y el Bierzo se registraron los mayores crecimientos. La cuenca berciana merece especial mención, pues en 1960 la mitad de las explotaciones carboneras leonesas operaban en ella. Como contrapartida, en consonancia con el tradicional minifundismo del sector de la antracita, la producción media en el Bierzo era la más reducida de las cuatro cuencas principales. Esto no obsta, sin embargo, para que el promedio berciano hubiera registrado un crecimiento considerable desde 1940, señal de que el auge de la antracita sirvió también para consolidar, en esta zona minera, empresas de notable dimensión. Todo lo contrario aconteció en la cuenca hullera de Sabero, que se convirtió, debido a la entrada de pequeños empresarios y al débil crecimiento de Hulleras de Sabero, en la única en la que descendió la producción media.

Tabla 2. Número de empresas y producción media (toneladas) en las cuencas leonesas en 1940 y 1960

\begin{tabular}{|c|c|c|c|c|c|c|}
\hline & \multicolumn{2}{|c|}{ Número } & \multirow{2}{*}{$\begin{array}{r}\text { Variación } \\
\%\end{array}$} & \multicolumn{2}{|c|}{ Producción media } & Variación \\
\hline & 1940 & 1960 & & 1940 & 1960 & $\%$ \\
\hline El Bierzo & 47 & 74 & 57,45 & $13.231,4$ & $20.350,8$ & 53,81 \\
\hline Ciñera-Matallana & 11 & 23 & 109,09 & $18.635,3$ & $23.334,1$ & 25,21 \\
\hline Sabero & 10 & 17 & 70,00 & $32.258,8$ & $20.823,5$ & $-35,45$ \\
\hline Valderrueda & 10 & 14 & 40,00 & $5.882,9$ & $6.892,0$ & 17,15 \\
\hline Villablino & 7 & 10 & 42,86 & $90.605,1$ & $100.523,6$ & 10,95 \\
\hline La Magdalena & 9 & 8 & $-11,11$ & $1.482,2$ & $9.231,5$ & 522,82 \\
\hline Cármenes-Vill. & 3 & 2 & $-33,33$ & $1.085,3$ & $5.893,0$ & 442,98 \\
\hline Totales & 97 & 148 & 52,58 & $19.166,1$ & $24.216,2$ & 26,35 \\
\hline
\end{tabular}

Fuente: Estadística General de Producción, Importación y Distribución Directa de Carbones Minerales 
El número de minas o grupos mineros se acrecentó aún más que el de empresas: un 108 por 100, al pasar de 96 en 1940 a 200 en 1960. Prácticamente lo mismo sucedió con la superficie afectada por las explotaciones, que superaba las 53.000 hectáreas en 1956, cuando en 1940, según la Estadística Minera y Metalúrgica de España, sólo alcanzaba las 25.000.

Tabla 3. Distribución de la producción leonesa en función del tamaño de las empresas en 1940 y 1960

\begin{tabular}{|c|c|c|c|c|}
\hline \multirow[t]{2}{*}{ Toneladas anuales } & \multirow[t]{2}{*}{1940} & \multirow[t]{2}{*}{1960} & \multicolumn{2}{|c|}{ Variación } \\
\hline & & & Absoluta & $\%$ \\
\hline Menos de 5.000 & 106.430 & 119.854 & 13.424 & 0,78 \\
\hline de 5.000 a 15.000 & 171.561 & 286.767 & 115.206 & 6,68 \\
\hline de 15.000 a 40.000 & 216.984 & 568.259 & 351.275 & 20,37 \\
\hline de 40.000 a 100.000 & 342.748 & 341.322 & -1.426 & $-0,08$ \\
\hline Más de 100.000 & 1.021 .388 & 2.267 .707 & 1.246 .319 & 72,26 \\
\hline Totales & 1.859 .111 & 3.583 .909 & 1.724 .798 & 100,00 \\
\hline
\end{tabular}

Tabla 4. Empresas carboneras leonesas con producción superior a 40.000 toneladas en 1940

\begin{tabular}{|c|c|c|c|c|}
\hline & & Cuenca & Toneladas & $\%$ \\
\hline 1 & MSP & Villablino & 537.875 & 28,9 \\
\hline 2 & Hulleras de Sabero & Sabero & 219.533 & 11,8 \\
\hline 3 & Antracitas Gaiztarro & El Bierzo & 137.368 & 7,4 \\
\hline 4 & Vasco-Leonesa & Ciñera-Matallana & 126.612 & 6,8 \\
\hline 5 & Diego Pérez Campanario & El Bierzo & 92.184 & 5,0 \\
\hline 6 & Esteban Corral & Sabero & 62.031 & 3,3 \\
\hline 7 & Moro, S. A. & El Bierzo & 50.040 & 2,7 \\
\hline 8 & Valle y Díez & Ciñera-Matallana & 47.949 & 2,6 \\
\hline 9 & Victoriano González Vega & EL Bierzo & 47.376 & 2,5 \\
\hline \multirow[t]{3}{*}{10} & Hijo de Baldomero García & Villablino & 43.168 & 2,3 \\
\hline & Resto & & 494.975 & 26,6 \\
\hline & Total (97 empresas) & & 1.859 .111 & 100,0 \\
\hline
\end{tabular}

La mitad de las nuevas empresas fueron de muy reducida dimensión (menos de 5.000 toneladas anuales de producción). La escasa relevancia de este segmento de la industria queda patente en la tabla 3: su actividad apenas tuvo incidencia en el aumento del carbón extraído en la provincia. Todo lo contrario aconteció en el grupo de las grandes compañías (más de 100.000 toneladas anuales), cuya nómina 
sólo se incrementó en una unidad (Antracitas de Fabero), pero aportó el 72 por 100 del incremento de la producción. A su lado, destacan también los productores medios (entre 15.000 y 40.000 toneladas), tanto por el aumento del número de entidades (especialmente intenso en el Bierzo) como por su contribución al crecimiento de la cantidad arrancada.

Tabla 5. Empresas carboneras leonesas con producción superior a 40.000 toneladas en 1960

\begin{tabular}{lllrr}
\hline \hline & & Cuenca & Toneladas & $\%$ \\
\hline \hline 1 & MSP & Villablino & 942.111 & 26,3 \\
2 & Vasco-Leonesa & Ciñera-Matallana & 504.161 & 14,1 \\
3 & Antracitas de Fabero & El Bierzo & 322.083 & 9,0 \\
4 & Hulleras de Sabero & Sabero & 266.900 & 7,4 \\
5 & Antracitas de Gaiztarro & El Bierzo & 232.452 & 6,5 \\
6 & Combustibles de Fabero & El Bierzo & 51.571 & 1,4 \\
7 & Antracitas de Brañuelas & El Bierzo & 51.317 & 1,4 \\
8 & Minas Sorpresas, S. A. & El Bierzo & 51.598 & 1,4 \\
9 & Victoriano González, S. A. & El Bierzo & 49.090 & 1,4 \\
10 & Domingo López Alonso & Sabero/Magdalena & 48.435 & 1,4 \\
11 & Antonio García Simón & El Bierzo & 47.317 & 1,3 \\
12 & Carbonífera Espina Tremor & El Bierzo & 41.994 & 1,2 \\
& Resto & & 974.880 & 27,2 \\
\hline \hline & Total (148 empresas con producción) & 3.583 .909 & 100,0 \\
\hline \hline
\end{tabular}

Fuente: Estadística General de Producción, Importación y Distribución Directa de Carbones Minerales

Las tablas 4 y 5 recogen las principales compañías carboneras leonesas en 1940 y 1960. Se trata de aquéllas que superaron las 40.000 toneladas anuales. Las 10 que cumplían este requisito en 1940 y las 12 que hacían lo propio en 1960 extrajeron más del 70 por 100 del carbón leonés. Un dato que pone de relieve el elevado grado de concentración de la industria, habida cuenta que las citadas compañías representaban un 10 y un 8 por 100 de las existentes en cada uno de los años mencionados.

Entre el resto de los hechos dignos de subrayar destacan, en primer lugar, la primacía de MSP, mantenida durante todo el período. En segundo, el notable avance de la Vasco-Leonesa, que prácticamente duplicó su importancia relativa. En tercero, la pérdida de posiciones de Hulleras de Sabero, que pasó desde el segundo al cuarto lugar, descenso provocado no sólo por el progreso de otros productores, sino también por su propia evolución. Finalmente, merece ser mencionada la irrupción de numerosas compañías bercianas en el grupo de las principales: en 
1960, las tres cuartas partes de las empresas que obtenían más de 40.000 toneladas anuales operaban en el Bierzo.

Los datos anteriores reafirman la idea de que el auge minero del período autárquico tuvo muy poco que ver con aquel otro que, unas décadas antes, había sido propiciado por la Primera Guerra Mundial. La mayor intensidad y menor duración de este último constituyen las diferencias más notables. Pero no fueron las únicas. El crecimiento de la producción carbonera entre 1914 y 1919 tuvo como auténticos responsables no a las grandes empresas, cuya actividad menguó, sino a los pequeños productores que entraron en el negocio atraídos por la elevada rentabilidad. A lo largo de los años cuarenta y cincuenta, sucedió algo muy distinto. Es cierto que durante la autarquía arribaron al sector innumerables empresarios carentes de recursos y medios apropiados. Pero su repercusión en la producción de las cuencas leonesas resultó insignificante. El verdadero impulso procedió de las compañías de mayor dimensión: las 33 empresas que en 1960 obtenían más de 15.000 toneladas anuales contribuyeron abrumadoramente a la evolución alcista del carbón extraído.

Esta expansión del negocio carbonero, de la mano, en general, de empresas de notable dimensión no bastó para contrarrestar la escasez de medios y la precariedad del trabajo en las minas, cuya más trágica consecuencia la constituyeron los accidentes y las catástrofes que todavía hoy, por la frecuencia con la que se sucedieron, sobrecogen el ánimo de quien repasa la prensa de la época. Acontecimientos desgraciados que en las minas leonesas acabaron con la vida de 701 trabajadores entre 1940 y $1959^{13}$, prácticamente un fallecido cada diez días.

Por otro lado, la política inversora y expansiva de las compañías más importantes no tuvo un reflejo demasiado brillante en la rentabilidad del negocio. Como se aprecia en la figura 3 la rentabilidad financiera de la Vasco-Leonesa se mantuvo, por lo general, entre el 3 y el 7 por 100, valores muy alejados de los alcanzados por este indicador durante la Gran Guerra (entre el 10 y el 60 por 100). Por tanto, en lo que a la rentabilidad se refiere, los años autárquicos no fueron negativos para la Vasco-Leonesa, pero tampoco resultaron especialmente brillantes.

¿Es extrapolable la situación de esta compañía al conjunto de la industria carbonera leonesa? Todo parece indicar que sí. No hay más que repasar las continuas quejas de los empresarios y los muy frecuentes abandonos de explotaciones o cambios en la propiedad de las empresas, para comprender que la

${ }^{13}$ Cifra obtenida de la Estadística Minera y Metalúrgica de España correspondiente a esos años. 
situación no debía de ser particularmente boyante. Únicamente mejoraba cuando se llevaban a cabo actividades de beneficio (aglomeración o coquización).

Figura 3. Rentabilidad financiera de la Vasco-Leonesa y de MSP, 1940-1960 (porcentaje que representa el resultado sobre los recursos propios)

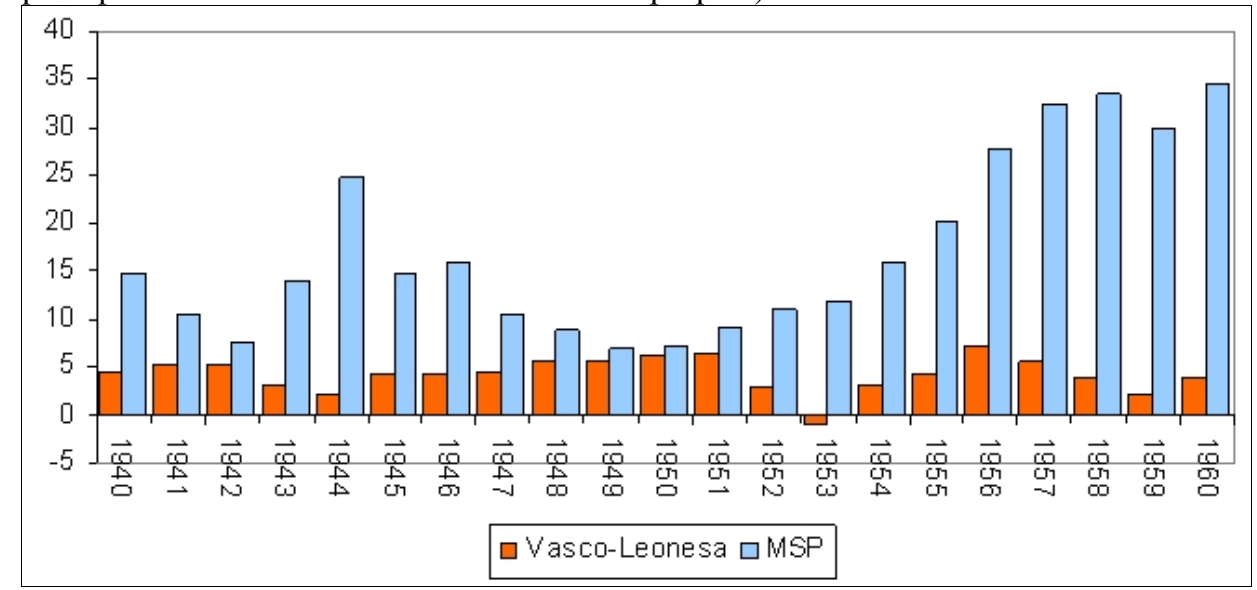

FUENTE: ANES y TASCÓN (1993) y VEGA (2003)

Sin embargo, la rentabilidad financiera de la principal empresa minera leonesa, MSP, parece poner en cuestión esta idea. La figura 3 incluye la evolución de la rentabilidad del productor lacianiego. Una rentabilidad que, tras un intenso crecimiento que se inicia en 1950, llega a alcanzar cotas extraordinarias, superiores al 30 por 100. ¿Cuál fue la clave de la espectacular diferencia entre la rentabilidad financiera de MSP y de la Vasco-Leonesa? Vega apunta algunas ideas al señalar que la Vasco-Leonesa se vio obligada «a acometer importantes inversiones para recuperar los destrozos ocasionados por la contienda civil» y resultó «perjudicada por el distinto trato legal que el Gobierno otorgó a la hulla y la antracita, combustible, este último, que la Vasco-Leonesa producía en mucha menor proporción que MSP»» ${ }^{14}$.

Aceptando estos argumentos, la causa fundamental de la diferente rentabilidad de las dos empresas debe buscarse fuera de la minería del carbón. La autora citada afirma al referirse a los resultados de la explotación carbonera de MSP:

\footnotetext{
14 Vega Crespo, Josefa (2003). Minero Siderúrgica de Ponferrada 1918-2010. Historia y futuro de la minería leonesa, Madrid: LID Editorial Empresarial, p. 154.
} 
La flexibilización de la política de precios o, en su defecto, la adaptación de éstos a la evolución seguida por los costes, era una de las medidas por las que la empresa había estado clamando durante todo el período autárquico ya que, argumentaba, los aumentos decretados en los precios no eran suficientes para cubrir la elevación de los costes que se producía, unas veces, como consecuencia de las disposiciones oficiales y, otras, por el descenso de los rendimientos.

Así pues, también en las minas de carbón de MSP «el margen entre el precio de venta y el coste de producción fue desde el principio muy estrecho» ${ }^{15}$. Este margen se ensanchó ciertamente con la fabricación de aglomerados (actividad que también llevaba a cabo la Vasco-Leonesa, y de la que ésta obtuvo en 1959 y 1960 unos beneficios que duplicaron a los de las minas), pero fundamentalmente con actividades ajenas a la minería del carbón. El diversificado negocio de MSP incluía un ferrocarril, dos centrales térmicas y, desde 1954, las minas de hierro del Coto Wagner, responsables, en especial estas últimas, de una parte muy sustancial de los beneficios obtenidos por la compañía que operaba en Villablino. Hasta el punto de que en 1960 el resultado de explotación de las minas de hierro superó incluso al generado por las de carbón.

En definitiva, la extracción de carbón no constituyó una actividad singularmente lucrativa ni para la Vasco-Leonesa ni para MSP, aunque para esta última lo fuera más que para la primera. La fabricación de aglomerados solucionó parcialmente el problema, pero no radicó ahí la causa determinante de los elevados beneficios de MSP, causa que debe buscarse en las secciones «no carboneras» de su negocio, y muy especialmente en la explotación del Coto Wagner.

Ante este panorama, la discusión sobre si la autarquía abrió una etapa de auge para la minería del carbón está plenamente justificada, salvo que la expresión se refiera únicamente a la evolución de la producción y del empleo. Ciertamente, los años que estaban por venir iban a resultar mucho más negativos para la industria nacional. Un empeoramiento que ya anunciaba, pese a la recuperación de 1960, la pronunciada caída que experimentaron los beneficios de la Vasco-Leonesa en 1958 y 1959. Pero lo que estaba sucediendo - el aumento de la competencia del fuel-oil, de la electricidad y del carbón importado; la reducción de las compras de clientes tradicionales como las azucareras, y el encarecimiento de algunos factores productivos - en modo alguno se puede considerar como la causa inicial de la crisis minera. La crisis estuvo siempre presente porque hunde sus raíces en las

\footnotetext{
${ }^{15}$ Vega CRespo, Josefa (2003). Minero Siderúrgica de Ponferrada 1918-2010. Historia y futuro de la minería leonesa, Madrid: LID Editorial Empresarial, p. 139.
} 
desfavorables características del carbón nacional. Es cierto que la política autárquica consiguió que se incrementara la producción carbonera, pero no lo hizo mejorando la productividad y la capacidad competitiva de las empresas. La evolución de los rendimientos indica que, salvo contadas excepciones, ocurrió precisamente lo contrario. Visto así, la autarquía, con su política de intervención, lo único que consiguió fue retrasar la fase aguda de la crisis, y, al mismo tiempo, incrementar sus potenciales efectos negativos al aumentar la altura desde la que sobrevendría el desplome de la industria nacional del carbón.

El examen de la minería leonesa durante estos trascendentales años no estaría completo si no hiciéramos referencia a la extraordinaria capacidad de esta industria para transformar el espacio geográfico que le servía de escenario. Muchas de estas mutaciones espaciales han llegado hasta nuestros días como una parte fundamental del legado minero.

\section{LA PROFUNDA TRANSFORMACIÓN DE LOS TERRITORIOS MINEROS LEONESES}

Ni la mecanización, ni las inversiones, ni las concentraciones impidieron que, en las cuencas leonesas como en el resto del país, para aumentar la producción fuese necesario incrementar el número de trabajadores. Y es que, como hemos tenido ocasión de comprobar, los esfuerzos realizados, especialmente durante los años cuarenta, no se tradujeron en una mejora de los rendimientos.

Estos requerimientos crecientes de mano de obra se encontraron con el problema recurrente de la escasez de trabajadores. No faltan las referencias a esta fundamental cuestión: «Sin tener en León la escasez de mano de obra caracteres tan agudos como en Asturias, no deja de notarse la falta de obreros para los trabajos mineros, especialmente en las zonas productoras de hulla de Sabero y Villablino» ${ }^{16}$.

En la memoria de la Vasco-Leonesa del ejercicio 1952, se lee: «Tenemos que hacer constar que durante todo el año, hemos venido padeciendo una gran escasez de personal especializado para las labores mineras, situación que también se ha agravado en los últimos tiempos».

Una preocupación que se reitera en la memoria del año siguiente: «Continuamos sufriendo la escasez de personal especializado y, a pesar de nuestros

16 Instituto Geológico y Minero de EsPañA: Estadística Minera y Metalúrgica de España (1946), p. 377. 
esfuerzos para la preparación del mismo, no nos ha sido posible cubrir todas nuestras necesidades dimanadas de nuestros proyectos de aumento de producción. Tememos, incluso, no podamos ocupar las casas que estamos terminando en Ciñera, con personal especializado».

Figura 4. Crecimiento demográfico de las comarcas y los municipios leoneses entre 1940 y 1960

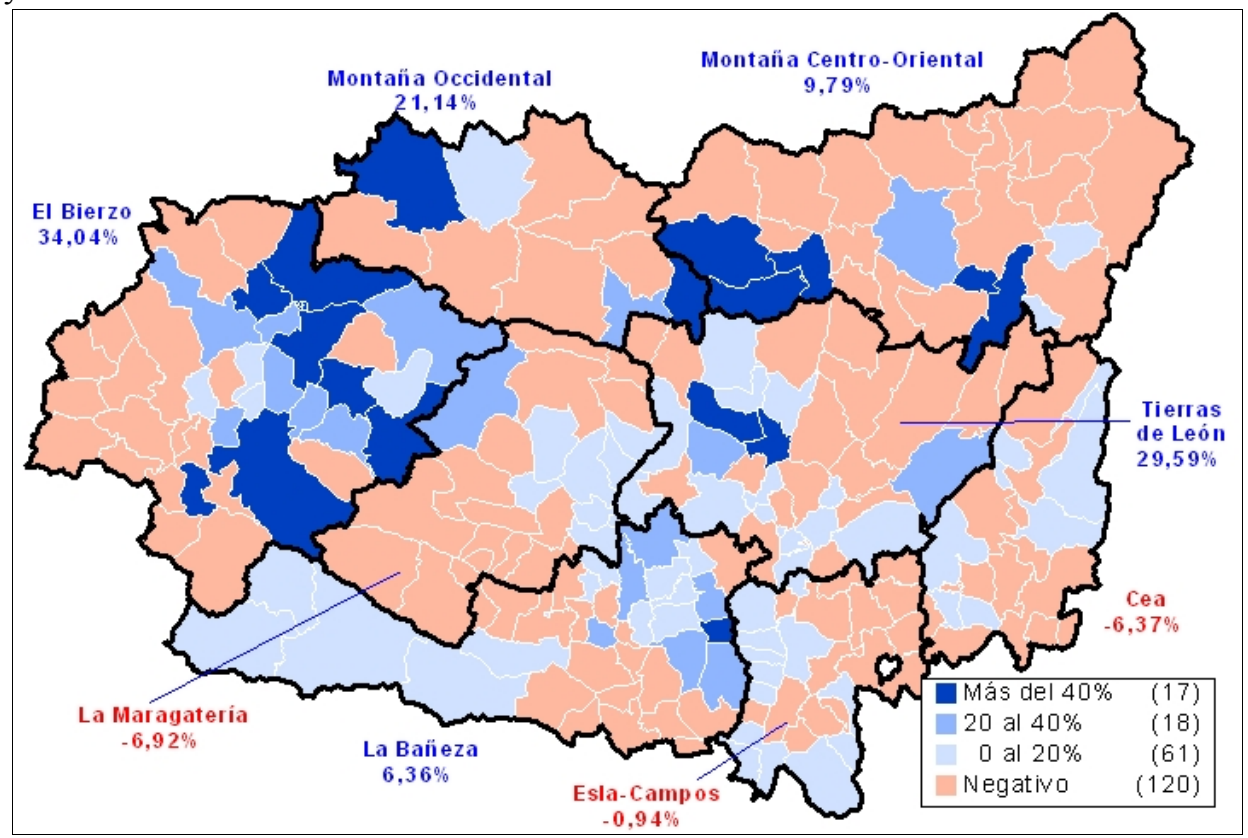

FUENTE: INE y Cámara Oficial de Comercio e Industria de León (2002)

El problema de la falta de mano de obra sólo tenía una solución. En unos territorios con una red de carreteras muy deficiente, y en una época en la que el escaso grado de desarrollo del transporte público y la práctica inexistencia del transporte privado no permitían los movimientos pendulares a los que hoy estamos tan acostumbrados, la inmigración aparecía como la única alternativa, una alternativa que, al hacer coincidir los lugares de trabajo y residencia, acortaba el tiempo de desplazamiento y abarataba su coste.

Pero el recurso a la inmigración no dejaba de ser una solución parcial, pues, como ponen de manifiesto las citas anteriores, el problema encerraba más una cuestión cualitativa que cuantitativa, esto es, lo que las compañías carboneras demandaban $-\mathrm{y}$ tenían dificultades para conseguir - era personal con la 
cualificación necesaria para trabajar en las minas. Aun así, el proceso dio comienzo $\mathrm{y}$, en el conjunto de la provincia (figura 4), hizo que fueran los municipios de las cuencas mineras los que registraran las más altas tasas de crecimiento demográfico: de los diecisiete municipios leoneses cuya población aumentó más de un 40 por 100 (tabla 6), doce (el 71 por 100) formaban parte de las cuencas mineras. La población de las cinco cuencas más significativas aumentó un 45 por 100 (tabla 7), cerca de tres veces más que la población provincial, que lo hizo un 16 por 100.

Tabla 6. Municipios leoneses cuyo crecimiento demográfico superó el 40 por 100 durante el período autárquico

\begin{tabular}{lrrrc}
\hline \hline & 1940 & 1960 & Var.(\%) & Cuenca minera \\
\hline \hline Fabero & 1.925 & 8.347 & 333,61 & El Bierzo \\
Ponferrada & 17.313 & 40.806 & 135,70 & \\
Toreno & 3.331 & 7.000 & 110,15 & El Bierzo \\
Villablino & 7.995 & 15.783 & 97,41 & Villablino \\
León & 45.531 & 77.583 & 70,40 & \\
San Andrés del Rabanedo & 4.844 & 7.699 & 58,94 & \\
Carrocera & 1.240 & 1.894 & 52,74 & La Magdalena \\
Matallana de Torío & 2.475 & 3.778 & 52,65 & Ciñera-Matallana \\
Torre del Bierzo & 3.474 & 5.279 & 51,96 & El Bierzo \\
La Robla & 3.039 & 4.545 & 49,56 & Ciñera-Matallana \\
Pola de Gordón (La) & 5.789 & 8.657 & 49,54 & Ciñera-Matallana \\
Sabero & 3.403 & 5.018 & 47,46 & Sabero \\
Páramo del Sil & 2.759 & 4.065 & 47,34 & El Bierzo \\
Bembibre & 4.193 & 6.141 & 46,46 & El Bierzo \\
Borrenes & 1.007 & 1.472 & 46,18 & \\
Cistierna & 4.792 & 6.927 & 44,55 & Sabero \\
Pobladura de Pelayo García & 722 & 1.041 & 44,18 & \\
\hline \hline
\end{tabular}

FUENTE: INE y Cámara Oficial de Comercio e Industria de León (2002)

Tabla 7. Población de derecho de las cuencas mineras leonesas más significativas, 1940, 1950 y 1960

\begin{tabular}{|c|c|c|c|c|c|c|}
\hline & \multirow[t]{2}{*}{1940} & \multirow[t]{2}{*}{1950} & \multirow[t]{2}{*}{1960} & \multicolumn{3}{|c|}{ Variación porcentual } \\
\hline & & & & $40-50$ & $50-60$ & $40-60$ \\
\hline Villablino & 12.794 & 16.584 & 20.581 & 29,62 & 24,10 & 60,86 \\
\hline El Bierzo & 39.068 & 43.464 & 58.821 & 11,25 & 35,33 & 50,56 \\
\hline Ciñera-Matallana & 13.424 & 15.206 & 18.797 & 13,27 & 23,62 & 40,03 \\
\hline Sabero & 10.727 & 12.025 & 14.337 & 12,10 & 19,23 & 33,65 \\
\hline Valderrueda & 5.078 & 5.221 & 4.914 & 2,82 & $-5,88$ & $-3,23$ \\
\hline Totales & 81.091 & 92.500 & 117.450 & 14,07 & 26,97 & 44,84 \\
\hline
\end{tabular}

FUENTE: INE y Cámara Oficial de Comercio e Industria de León (2002) 
No obstante, los espectaculares registros demográficos del conjunto de las zonas mineras leonesas no deben ocultar las notables diferencias que existían entre ellas. El crecimiento porcentual de la cuenca de Villablino fue un 81 por 100 más alto que el correspondiente a la cuenca de Sabero, y un 52 por 100 superior al de Ciñera-Matallana. De la misma forma, la población de la cuenca minera berciana aumentó un 50 y un 26 por 100 más que la de Sabero y Ciñera-Matallana, respectivamente. El mayor dinamismo de la minería berciana durante los cincuenta se plasmó en un incremento demográfico que superó a los de Sabero y CiñeraMatallana en un 84 y un 50 por 100. En el otro extremo, la cuenca de Valderrueda continuaba con su secular estancamiento. Como es lógico, estas diferencias se acentuaron considerablemente a escala municipal, donde el crecimiento demográfico de municipios como Sabero, aun siendo notable, se quedó muy lejos del experimentado por otros como Fabero o Toreno.

El centro de gravedad de la minería leonesa se desplazaba cada vez más hacia el oeste. A ello contribuía el viento favorable del auge de la antracita y unos yacimientos más fáciles de explotar, pero, sobre todo, el impulso de unos mercados más consolidados y un mayor espíritu emprendedor. No olvidemos que ya en 1900, antes de que la minería alcanzara significación económica en el Bierzo, esta comarca era, con diferencia, la más poblada de la provincia. En cambio, al este del Bernesga la falta de iniciativa empresarial será el muro contra el que se estrellarán, una tras otra, todas las políticas de desarrollo.

La progresiva llegada de inmigrantes a las cuencas mineras, sin poner fin a la penuria de especialistas, agudizó otro problema: el de la vivienda y las infraestructuras. Una cuestión de la que se hacía eco la Estadística Minera de 1946: «La falta de viviendas en las zonas mineras es otro problema que debería resolverse. Haría falta construir doscientas viviendas para obreros en cada una de las zonas de Villablino, Santa Lucía, Sabero y Fabero» ${ }^{17}$.

Las primeras interesadas en abordar este asunto fueron, por supuesto, las propias compañías mineras. Pero la Administración, en aquellos momentos, no debía de confiar demasiado en el supuesto paternalismo empresarial. Así, con carácter general, obligó a las empresas españolas a dedicar una parte de sus beneficios a «facilitar al obrero y su familia vivienda acogedora e higiénica», siempre que por la índole de sus actividades tuvieran centros de trabajo permanentes, tales como minas, fábricas, talleres, explotaciones agrícolas, etc.

${ }^{17}$ Instituto Geológico y Minero De EsPaña: Estadística Minera y Metalúrgica de España (1946), p. 378. 
Concretamente, desde el 1 de julio de 1943 debían destinar a fines de carácter social, y preferentemente a la construcción de viviendas, el 20 por 100 de una reserva especial, dotada con una parte de los beneficios extraordinarios, a los que, a tal fin, se les aplicaba una escala que iba desde el 40 al 80 por $100^{18}$.

La obligación anterior fue objeto de una mayor precisión en $1946^{19}$, al tiempo que se habilitaban diversas ventajas para que las empresas pudieran cumplirla con mayor facilidad. Éstas debían facilitar alojamiento familiar a su personal en los casos de nuevas explotaciones permanentes en las que se fueran a emplear a $50 \mathrm{o}$ más productores, siempre que, para acceder al lugar de trabajo, no se dispusiera de medios de comunicación fáciles y debieran cubrirse a pie distancias superiores a tres kilómetros. Si estas circunstancias ya se daban en alguna de las explotaciones existentes, la empresa venía obligada a emplear íntegramente a tal fin el 20 por 100 de la reserva especial. La construcción de viviendas nuevas para cumplir con esta norma daba derecho a acogerse a los beneficios de la legislación de protección de la vivienda de renta reducida, previa presentación del proyecto ante el Instituto Nacional de la Vivienda. Esos beneficios, extensivos a las construcciones complementarias (religiosas, culturales, deportivas, etc.), incluían bonificaciones tributarias, anticipo sin interés por el 40 por 100 del presupuesto de construcción, preferencia en la adquisición de materiales y expropiación forzosa de los terrenos. Las viviendas construidas por las empresas podían ser dadas en amortización a sus obreros o quedar en propiedad de las mismas. En este caso, el contrato de alquiler era accesorio del contrato de trabajo.

A partir de los ejercicios terminados el 31 de diciembre de 1947, cesó la obligación de constituir la reserva especial, salvo en la parte correspondiente a las

${ }^{18}$ Se consideraban beneficios extraordinarios los que excedieran del promedio de los obtenidos en el trienio inmediatamente anterior al 18 de julio de 1936, o los que excedieran del 7 por 100 del capital si la empresa en dicha fecha no llevaba tres años completos de actividad. Primero estuvo vigente un impuesto que gravaba estos beneficios (Ley de 17 de octubre de 1941 por la que se estableció la vigencia de la contribución excepcional sobre beneficios extraordinarios creada por la Ley de 5 de enero de 1939). Este gravamen cesó el 1 de julio de 1943 sustituido por la obligación de constituir una reserva por un importe equivalente (Ley de 30 de diciembre de 1943). El 20 por 100 de esta reserva debía destinarse «al mejoramiento de las condiciones de trabajo y vida de los trabajadores de la empresa». El Decreto de 3 de marzo de 1944 (BOE 76) estableció el carácter preferente de la construcción de viviendas dentro de esos fines sociales.

${ }^{19}$ Ley de 17 de julio de 1946 sobre construcción de viviendas protegidas por las empresas industriales (BOE 199 de 18 de julio). 
atenciones de carácter social, que siguieron en pie cuando el dividendo acordado fuera equivalente o superior al 7 por 100 del capital fiscal de la empresa ${ }^{20}$.

Pese a las disposiciones anteriores, en 1955 la cuestión de la vivienda seguía en el primer plano de las preocupaciones sociales. Así se reconocía en el escueto exordio de un Decreto de 27 de mayo, sobre construcción de viviendas por empresas industriales en sus instalaciones, donde al referirse al «acuciante problema de la vivienda» se reconocía que «por su escasez, especialmente en cuanto a la vivienda barata, constituye hoy para el elemento obrero y empleados modestos, la mayor dificultad en cuanto al normal desenvolvimiento de la vida familiar $\rangle^{21}$. Esta norma obligó a construir viviendas para los trabajadores en los casos de creación, ampliación o traslado de una industria si el lugar donde se iba a realizar la actividad carecía de ellas.

Asimismo, en dicho año una norma autorizó a las empresas para invertir el 20 por 100 de la reserva especial en la concesión a sus trabajadores de anticipos o préstamos, con garantía hipotecaria y un tipo de interés máximo del 3 por 100 anual, para que éstos pudieran adquirir o construir por su cuenta su propia vivienda ${ }^{22}$.

En las cuencas mineras, las medidas anteriores no bastaron para resolver el problema. De ahí que la Administración, tan empeñada en el incremento de la producción de carbón y consciente de que la iniciativa privada resultaba insuficiente para promover las viviendas necesarias para fijar población en las zonas carboneras, interviniera directamente por medio del Instituto Nacional de la Vivienda. En el caso concreto de las cuencas leonesas, se encomendó a este organismo la construcción urgente de 1.500 viviendas en $1950^{23}$, y de otras 1.500 en $1954^{24}$. Si bien este último proyecto no llegó a realizarse debido a que la creación del Ministerio de la Vivienda en 1957 supuso la puesta en marcha de una nueva modalidad de protección (las viviendas subvencionadas), menos generosa que la anterior de viviendas protegidas.

${ }^{20}$ Decreto de 9 de abril de 1948 (BOE 102 de 11 de abril) y Orden de 1 de julio de 1948 (BOE 164 de 12 de junio).

21 BOE número 170 de 19 de junio de 1955.

22 Decreto de 29 de abril de 1955 (BOE 158 de 7 de junio).

${ }^{23}$ Decreto de 5 de junio de 1950 (BOE 195 de 14 de julio).

${ }^{24}$ Decreto de 2 de julio de 1954 (BOE 205 de 24 de julio). 
Resumiendo, tanto las compañías carboneras, obligadas por la normativa y aprovechando los beneficios legales, como el Estado reaccionaron frente a la escasez de alojamientos construyendo viviendas sociales. Casi siempre lo hicieron, como afirma Roiz, de forma muy desafortunada y con notorias consecuencias urbanísticas. Las viviendas que se levantaron fueron baratas, de mala calidad y reducido espacio. Lo usual era que las propias empresas las administraran y se las alquilaran a sus trabajadores. Un régimen de tenencia que, para el autor citado, representaba «un arma de atadura y dominio de la mano de obra, ya que el contrato de inquilinato va unido al contrato laboral y la rotura de éste o el despido provoca automáticamente el desahucio» ${ }^{25}$. El sistema constituía, sin duda, un problema para el minero, que se veía en la obligación de dejar la vivienda también en el caso de jubilación. Estas circunstancias y la deficiente calidad de las construcciones explican que el trabajador percibiera la casa de la empresa como una solución transitoria, y que tal falta de identificación se tradujera en un alto porcentaje de abandono de estas viviendas, una vez que, alcanzado un determinado nivel de vida, el minero se encontraba en condiciones de adquirir una casa mejor.

Las actuaciones constructoras unas veces se llevaron a cabo dentro de aquellos pueblos mineros que ya tenían un cierto tamaño (como ocurrió en Olleros con las colominas); y otras, junto a las mismas explotaciones o en sus cercanías. En este caso desembocaron en la proliferación de poblados mineros, creados artificialmente por las empresas en terrenos separados de los núcleos campesinos (los cuarteles de Veneros, por ejemplo) o generados a partir de pequeñas aldeas, como fue el caso de Ciñera. Casi todos tenían en común sus viviendas baratas, construidas con materiales de mala calidad, con huecos pequeños, mala estructura y poco espacio, agrupadas en bloques de dos a seis plantas, y dispuestas en formaciones lineales o cuadradas. Unas peculiaridades acordes con la provisionalidad que les era propia. En la provincia de León, sólo Ciñera se alejó positivamente de las características señaladas.

Esta pequeña localidad, que experimentó un intenso crecimiento, pasando de 300 habitantes en 1940 a 1.600 en 1960, se puede tomar como ejemplo de las profundas mutaciones territoriales originadas por la industria extractiva. La VascoLeonesa no sólo construyó en ella las 194 viviendas que, en la forma de casas unifamiliares pareadas, aún ocupan aproximadamente la mitad occidental de Ciñera confiriéndole su peculiar fisonomía; además, la minería trajo a este núcleo ubicado junto al Bernesga servicios antes impensables: varias escuelas nacionales de

\footnotetext{
${ }^{25}$ RoIz, Miguel (1973). «Urbanismo y hábitat en la zona minera de León». Ciudad y Territorio, número 2, p. 55.
} 
enseñanza primaria, un campo de deportes en los terrenos del antiguo apartadero Iglesias, un casino, un economato de empresa, el cine Emilia, el taller de costura de las Hermanas Carmelitas, el restaurante La Hornaguera, etc.

A tenor de lo expuesto, se puede afirmar que los años cuarenta y cincuenta dibujaron una etapa fundamental en la historia de la industria carbonera leonesa. En el caso de que hayamos conseguido nuestros objetivos, hemos demostrado, en primer lugar, que la restricción autárquica estimuló de manera desmedida el crecimiento de la minería del carbón, especialmente durante los años cuarenta, cuando esta actividad se expandió de forma inverosímil sobre la base de la más pura ineficiencia. Y, en segundo lugar, que esta industria del carbón hipertrofiada se convirtió en una poderosa fuerza que transformó radicalmente el marco espacial que le servía de escenario. La industria extractiva dio ocupación a multitud de personas, impulsó el crecimiento de pequeños núcleos rurales, levantó en ellos viviendas, escuelas, campos de deporte, casinos, cines, economatos, etc. Pese a que muchos hombres dejaron su salud o su vida en la mina, el carbón se convirtió en sinónimo de progreso, de desarrollo de zonas atrasadas que sin él no hubieran salido nunca de su secular atraso y postración.

Pero ¿se trataba realmente de desarrollo? Este interrogante surge inevitable al comprobar cómo ese mundo diseñado a la medida de las grandes compañías carboneras comenzó a tambalearse justo cuando el país cambió de rumbo y el paréntesis autárquico empezó a cerrarse para todos, también para la industria del carbón. La participación de España en organismos como la ONU, el Fondo Monetario Internacional, el Banco Mundial o la OCDE era la prueba más palpable del reconocimiento oficial de que el abstruso objetivo de la autosuficiencia carecía de sentido más allá de la retórica política. Apenas se entreabrieron las fronteras del país, el desarrollo económico prendió con fuerza y se inauguró una nueva etapa que cambiaría profundamente la forma de vida de los españoles. Una etapa que pondría de manifiesto la verdadera consistencia de los cimientos sobre los que descansaba toda la estructura de las cuencas mineras.

\section{BIBLIOGRAFÍA}

ANES ÁlVAREZ, Rafael y Luis Julio TASCÓN FERNÁNDEZ (1993). Hullera Vasco-Leonesa: los cien primeros años de su historia, s. 1.: Sociedad Anónima Hullera Vasco-Leonesa.

BANCO EXTERIOR DE EsPaÑa (1968). Hechos y cifras de la economía española, 1967, Madrid: Nuevas Gráficas.

CÁmara Oficial de Comercio e Industria de León (2002). Cámara de León. Cien años de economía leonesa, León.

COLL MARTín, Sebastián y Carles SUdRIÀ I TRIAY (1987). El carbón en España, 17701961: una historia económica, Madrid: Turner. 
García Alonso, José María (1986). «La minería del carbón». Papeles de Economía Española, número 29, pp. 110-140.

GARcía Alonso, José María y Juan E. IRANZO MARTín (1988). La energía en la economía mundial y en España, Madrid: Editorial AC.

RoIZ, Miguel (1973). «Urbanismo y hábitat en la zona minera de León». Ciudad y Territorio, número 2, pp. 49-66.

SEN Rodríguez, Luis Carlos (1993). La minería leonesa del carbón, 1764-1959: una historia económica, León: Universidad de León.

Sindicato NACiONAL Del Combustible (1961). La minería del carbón en España, Madrid: Artes Gráficas Sol.

Vega Crespo, Josefa (2003). Minero Siderúrgica de Ponferrada 1918-2010. Historia y futuro de la minería leonesa, Madrid: LID Editorial Empresarial.

\section{FUENTES}

ARChivo DE LA Fundación Hullera VASCo-LeOnesa: memorias de la Sociedad Anónima Hullera Vasco-Leonesa.

BiBlioteCA DEL Ministerio DE ECONOMÍA Y HACIENDA: Estadística General de Producción, Importación y Distribución Directa de Carbones Minerales.

Biblioteca Pública de León (HemeroteCA): Diario de León.

Instituto GeolóGico y Minero de EsPaÑA: Estadística Minera de España. Denominada durante un tiempo Estadística Minera y Metalúrgica de España.

INSTITUTO NACIONAL DE ESTADÍSTICA: Censos de población.

Ministerio de la Presidencia: BAses de dATOs del Boletín Oficial del Estado (www.boe.es): Gaceta de Madrid, colección histórica, 1875-1967. 